\title{
Functional promoter polymorphisms of the macrophage migration inhibitory factor gene in gastric carcinogenesis
}

\author{
TOMIYASU ARISAWA ${ }^{1}$, TOMOMITSU TAHARA ${ }^{1}$, TOMOYUKI SHIBATA ${ }^{1}$, MITSUO NAGASAKA ${ }^{1}$, \\ MASAKATSU NAKAMURA ${ }^{1}$, YOSHIO KAMIYA ${ }^{1}$, HIROSHI FUJTTA ${ }^{1}$, DAISUKE YOSHIOKA ${ }^{1}$, YUKO ARIMA ${ }^{1}$, \\ MASAAKI OKUBO $^{1}$, ICHIRO HIRATA ${ }^{1}$, HIROSHI NAKANO ${ }^{1}$ and VIDAL DE LA CRUZ ${ }^{2}$ \\ ${ }^{1}$ Department of Gatroenterology, Fujita Health University School of Medicine, \\ 1-98 Dengakugakubo, Kutsukake-cho, Toyoake 470-1192, Japan; ${ }^{2}$ Business Development, \\ Cytokine PharmaSciences Inc., 150 South Warner Road, Suite 420, King of Prussia, PA 19406, USA
}

Received August 28, 2007; Accepted October 8, 2007

\begin{abstract}
The macrophage migration inhibitory factor (MIF) is a key proinflammatory mediator. Two functional polymorphisms have been identified in the promoter region of the MIF gene. We attempted to clarify the associations of these polymorphisms with the development of gastric cancer. The study was performed in 229 patients with gastric cancer and 428 subjects with no evidence of gastric malignancies on the upper gastro-duodenal endoscopy. The severity of histological chronic gastritis was classified according to the updated Sydney system. Overall, the 5-CATT carriers had a reduced risk of developing gastric cancer (OR, 0.67; 96\% CI, 0.48$0.93 ; \mathrm{p}=0.015)$, especially the diffuse type cancer. In subjects $>60$ years, the adjusted risk for gastric cancer among individuals who were -173C carriers was 1.71 (range, 1.03$2.84 ; \mathrm{p}=0.038$ ) compared to the $\mathrm{G} / \mathrm{G}$ homozygous genotype. The number of 7-CATT alleles was also positively correlated with the development of intestinal type gastric cancer (adjusted OR, 1.70; 95\% CI, 1.02-2.58; $\mathrm{p}=0.043$ ). In subjects $<60$ years, the 7/7-CATT homozygous genotype was linked with a risk for the progression of atrophic gastritis (adjusted OR, 8.74; 95\% CI, 1.31-58.6; $\mathrm{p}=0.026$ ). In addition, the number of 7CATT alleles was significantly correlated with the activity and inflammation scores ( $\mathrm{p}=0.010$ and 0.030 , respectively). Our results suggested that functional promoter polymorphisms of the MIF gene are associated with the progression of gastric mucosal inflammation and the development of mucosal atrophy at an early stage in life and these genotypes
\end{abstract}

Correspondence to: Dr Tomiyasu Arisawa, Department of Gastroenterology, Fujita Health University School of Medicine, 1-98 Dengakugakubo, Kutsukake-cho, Toyoake 470-1192, Japan E-mail: tarisawa@fujita-hu.ac.jp

Key words: macrophage migration inhibitory factor, gene polymorphism, gastric cancer may increase the risk for the subsequent development of gastric cancer, especially the intestinal type, in older subjects.

\section{Introduction}

Gastric cancer is one of the most common cancers worldwide, but the etiology of this tumor remains unclear. Infection with Helicobacter pylori (H. pylori) leads to persistent colonization and chronic inflammation of the gastric mucosa, thereby increasing the risk of developing peptic ulceration and gastric adenocarcinoma (1). However, there are marked interindividual differences in the extent of inflammation among persons with the $H$. pylori infection, so clinical consequences only develop in a small subgroup. Although bacterial virulence factors are associated with enhanced inflammation and cancer development $(2,3)$, it is unclear why a considerable proportion of patients infected with cag ${ }^{+}$ $H$. pylori strains do not develop severe pathologies throughout life. In addition to bacterial factors, mostly unknown host factors, such as genetic predisposition and host immunity, seem to influence the inflammatory response and the development of a more severe pathology. H. pylori-induced inflammation is implicated in the development of mucosal damage and is characterized by strong granulocytic and lymphocytic infiltration $(4,5)$. The $\mathrm{T}$ helper cell response to $H$. pylori is considered to be dependent on type 1 helper (Th1) cells, but the factors influencing this immune response to the H. pylori infection are largely unknown. Important cytokines that are related to Th1-mediated responses and are upregulated during chronic $H$. pylori infection include interferon- $\gamma$, tumor necrosis factor and interleukin-1ß (6-8).

The macrophage migration inhibitory factor (MIF) was originally identified as an activity isolated from $\mathrm{T}$ lymphocytes that was capable of inhibiting the random migration of macrophages $(9,10)$. The human MIF cDNA was finally cloned in 1989 (11). MIF is a key proinflammatory mediator that plays a pivotal role in inflammatory and immune diseases (12). It contributes toward an excessive inflammatory response directly, via an induction of proinflammatory cytokine secretion (13), and indirectly through its ability to override the antiinflammatory activity of glucocorticoids (14). These 
mechanisms suggest critical roles for MIF in various cancers (15). Recently, Xia et al reported that the H.pylori infection increased the MIF expression in both gastric inflammatory and epithelial cells (16), thus MIF may play an important role in H.pylori related gastric inflammation.

Polymorphisms with potential functional relevance have been identified in the MIF gene promoter. Moreover, an SNP at the nucleotide position -173 ( $\mathrm{G}$ to $\mathrm{C}$ ) (17) and a tetranucleotide CATT repeat beginning at position -794 (18) have been found to be associated with altered levels of the MIF gene transcription in vitro. Although it has been demonstrated that the functional importance of these variants includes findings of significant association with several immunemediated inflammatory diseases (17-19), the roles of these polymorphisms in the development of gastric disorders remain unclear.

In the present study, we attempted to clarify the associations of $\mathrm{G}-173 \mathrm{C}$ and -794 tetranucleotide repeats in the MIF gene promoter with gastric carcinogenesis.

\section{Materials and methods}

Clinical samples. As a gastric cancer group, 232 patients with gastric cancer (GC group), who were enrolled at the Endoscopy Center of Fujita Health University Hospital in 2006, were selected. As a control group, 430 subjects without malignant neoplasm were randomly selected from our stock DNA collected during the same period (non-GC group). The studied population comprised of 657 subjects whose polymorphisms could be clearly analyzed, including 229 in the GC group and 428 in the non-GC group.

All patients underwent upper gastrointestinal endoscopy and, in some of them, biopsy specimens were taken from antral mucosa. Parts of each specimen were fixed in $10 \%$ buffered formalin and embedded in paraffin, while the other parts were immediately frozen and stored at $-80^{\circ} \mathrm{C}$. All histological diagnoses were conducted at the Division of Pathology at our hospital. The severity of chronic gastritis was also classified according to the updated Sydney system by a pathologist who had no access to any clinical information. According to the severity of gastric mucosal atrophy, the subjects were divided into the following 2 groups: the atrophic gastritis group (atrophy score $\geq 2$ ) and the non-atrophy group (atrophy score $\leq 1$ ). The $H$. pylori infection status was assessed by serology, histological examination or the urea breath test. Patients were diagnosed as having infection when at least one of the diagnostic tests was positive.

The ethics committee of Fujita Health University School of Medicine approved the protocol and written informed consent was obtained from all of the participating subjects.

Genotyping of the polymorphisms. The stock DNAs isolated from biopsy specimens or peripheral blood were used. Polymorphism was genotyped by the PCR-SSCP method as previously reported $(20,21)$. To detect the -794 tetranucleotide repeat using the primer pair (MIFTRF: 5'-TGATCCAGTTG CTGCCTTGTC-3' and MIFTRR: 5'-TCCACTAATGGT AAACTCGGGGAC-3'), PCR was carried out in a volume of $20 \mathrm{ml}$ containing $0.1 \mu \mathrm{g}$ of genomic DNA. The DNA was denatured at $95^{\circ} \mathrm{C}$ for $3 \mathrm{~min}$, followed by 35 cycles at $95^{\circ} \mathrm{C}$
Table I. Characteristics of the subjects and frequencies of genotypes.

\begin{tabular}{|c|c|c|}
\hline & non-GC group & GC group \\
\hline No. of subjects & 428 & 229 \\
\hline Mean age \pm SD & $54.72 \pm 18.84$ & $62.99 \pm 10.73$ \\
\hline Male : female & $253: 175$ & $163: 66$ \\
\hline HP-positive rate & $66.0 \%$ & $90.7 \%$ \\
\hline \multicolumn{3}{|l|}{ n-CATT repeat } \\
\hline $5 / 5$ & 66 & 36 \\
\hline $5 / 6$ & 143 & 54 \\
\hline $5 / 7$ & 59 & 30 \\
\hline $5 / 8$ & 0 & 1 \\
\hline $6 / 6$ & 76 & 50 \\
\hline $6 / 7$ & 75 & 46 \\
\hline $6 / 8$ & 0 & 1 \\
\hline $7 / 7$ & 9 & 11 \\
\hline 5-CATT frequency & $39.0 \%$ & $34.3 \%$ \\
\hline 6-CATT frequency & $43.2 \%$ & $43.9 \%$ \\
\hline 7-CATT frequency & $17.8 \%$ & $21.4 \%$ \\
\hline 8-CATT frequency & $0 \%$ & $0.44 \%$ \\
\hline \multicolumn{3}{|l|}{ G-173C genotype } \\
\hline $\mathrm{G} / \mathrm{G}$ & 261 & 123 \\
\hline $\mathrm{G} / \mathrm{C}$ & 144 & 94 \\
\hline $\mathrm{C} / \mathrm{C}$ & 23 & 12 \\
\hline$-173 \mathrm{C}$ frequency & $22.2 \%$ & $25.8 \%$ \\
\hline
\end{tabular}

for $30 \mathrm{sec}, 62^{\circ} \mathrm{C}$ for $40 \mathrm{sec}$ and $72^{\circ} \mathrm{C}$ for $45 \mathrm{sec}$, with a final extension at $72^{\circ} \mathrm{C}$ for $5 \mathrm{~min}$. Thereafter, $2 \mathrm{ml}$ of the PCR product was denatured with $10 \mathrm{ml}$ of formamide (SigmaAldrich Co., St. Louis, USA) at $90^{\circ} \mathrm{C}$ for $5 \mathrm{~min}$. SSCP was carried out at $6^{\circ} \mathrm{C}$ using a GenePhor DNA separation system with GeneGel Excel 12.5/24 (Amersham Biosciences Corp., USA), after which the denatured single-strand DNA bands were detected using a DNA silver staining kit (Amersham Biosciences Corp.).

To detect the G-173C polymorphism using the primer set (MIF173F: 5'-TCTAGCCGCCAAGTGGAGAACA-3' and MIF173R: 5'-ACTGTGGTCCCGCCTTTTGTGA-3'), the $\mathrm{PCR}$ reaction was carried out with $60^{\circ} \mathrm{C}$ annealing temperature as described above. SSCP was also carried out as described above.

Statistical analysis. The strength of association between the allele frequencies and the disease was assessed by calculating the odds ratio (OR) and $95 \%$ confidence intervals (CI) by logistic regression analysis using a genotype as a variate or the number of alleles as a co-variate. Adjusted ORs were calculated with the use of logistic regression analysis after adjustment for age, gender and the $H$. pylori infection status. The Mann-Whitney U test and linear regression analysis were employed to test the association between MIF promoter polymorphisms and the updated Sydney system score. For all analyses, the level of significance was set at $\mathrm{p}<0.05$. 
Table II. Association between the MIF polymorphisms and gastric cancer.

\begin{tabular}{|c|c|c|c|c|c|c|}
\hline & \multicolumn{2}{|c|}{ 5-CATT cancer vs the others } & \multicolumn{2}{|c|}{ The number of 7-CATT alleles ${ }^{\mathrm{a}}$} & \multicolumn{2}{|c|}{$-173 \mathrm{C}$ carrier vs the others } \\
\hline & Unadjusted OR & Adjusted $\mathrm{OR}^{\mathrm{b}}$ & Unadjusted OR & Adjusted OR ${ }^{\mathrm{b}}$ & Unadjusted OR & Adjusted $\mathrm{OR}^{\mathrm{b}}$ \\
\hline \multicolumn{7}{|l|}{ Overall } \\
\hline Gastric cancer & $0.67(0.48-0.93)^{\mathrm{c}}$ & $0.83(0.56-1.23)$ & $1.31(0.98-1.75)$ & $1.04(0.72-1.48)$ & $1.35(0.97-1.86)$ & $1.22(0.82-1.80)$ \\
\hline Intestinal type & $0.70(0.47-1.03)$ & $0.79(0.49-1.27)$ & $1.38(0.98-1.95)$ & $1.23(0.80-1.87)$ & $1.47(0.99-2.18)$ & $1.59(0.99-2.54)$ \\
\hline Diffuse type & $0.64(0.41-0.99)^{\mathrm{d}}$ & $0.96(0.56-1.66)$ & $1.22(0.81-1.83)$ & $0.74(0.44-1.26)$ & $1.19(0.76-1.87)$ & $0.79(0.45-1.38)$ \\
\hline \multicolumn{7}{|l|}{$\leq 60$ years } \\
\hline Gastric cancer & $0.86(0.52-1.42)$ & $0.81(0.41-1.64)$ & $0.89(0.56-1.42)$ & $0.70(0.37-1.33)$ & $1.03(0.63-1.69)$ & $0.76(0.40-1.47)$ \\
\hline Intestinal type & $1.19(0.59-2.42)$ & $0.94(0.36-2.43)$ & $0.82(0.43-1.57)$ & $0.79(0.32-1.93)$ & $1.13(0.59-2.17)$ & $1.01(0.43-2.37)$ \\
\hline Diffuse type & $0.66(0.35-1.23)$ & $0.78(0.35-1.77)$ & $0.95(0.53-1.72)$ & $0.64(0.29-1.39)$ & $0.96(0.51-1.79)$ & $0.63(0.28-1.42)$ \\
\hline \multicolumn{7}{|l|}{$>60$ years } \\
\hline Gastric cancer & $0.59(0.38-0.92)^{\mathrm{e}}$ & $0.71(0.43-1.18)$ & $1.65(1.12-2.43)^{\mathrm{g}}$ & $1.47(0.93-2.34)$ & $1.65(1.07-2.56)^{\mathrm{j}}$ & $111.71(1.03-2.84)$ \\
\hline Intestinal type & $0.59(0.36-0.98)^{\mathrm{f}}$ & $0.63(0.35-1.11)$ & $1.71(1.10-2.64)^{\mathrm{h}}$ & $1.70(1.02-2.85)^{\mathrm{i}}$ & $1.73(1.05-2.85)^{\mathrm{k}}$ & $2.10(1.17-3.75)^{\mathrm{m}}$ \\
\hline Diffuse type & $0.60(0.31-1.13)$ & $0.98(0.45-2.12)$ & $1.58(0.89-2.78)$ & $0.98(0.47-2.05)$ & $1.51(0.80-2.87)$ & $1.06(0.48-2.31)$ \\
\hline
\end{tabular}

aThe number of 7-CATT alleles was used as a co-variate. ${ }^{b}$ Adjusted for gender, age and the $H$. pylori infection status. Data are shown as OR (95\% confidence intervals); ${ }^{\mathrm{c}} \mathrm{p}=0.015,{ }^{\mathrm{d}} \mathrm{p}=0.045,{ }^{\mathrm{e}} \mathrm{p}=0.019,{ }^{\mathrm{f}} \mathrm{p}=0.040,{ }_{\mathrm{g}}^{\mathrm{g}} \mathrm{p}=0.011,{ }^{\mathrm{h}} \mathrm{p}=0.017,{ }_{\mathrm{i}} \mathrm{p}=0.043,{ }^{\mathrm{j}} \mathrm{p}=0.025,{ }^{\mathrm{k}} \mathrm{p}=0.033 .{ }^{\mathrm{l}} \mathrm{p}=0.038$ and ${ }^{\mathrm{m}} \mathrm{p}=0.012$.

a)

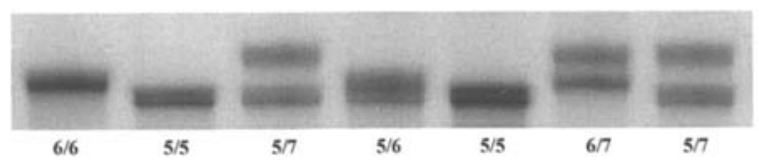

b)

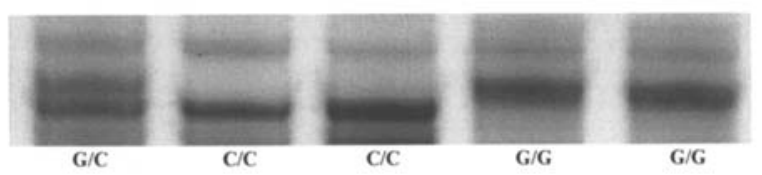

Figure 1. The images of PCR-SSCP using clinical samples. (a) Identification of the tetranucleotide (CATT) repeats (5/7) at position -794. (b) Identification of nucleotide $(\mathrm{G} / \mathrm{C})$ at position -173 .

\section{Results}

The characteristics of subjects and the frequencies of genotypes. As shown in Fig. 1, single-strand DNAs of both -794 tetranucleotide repeats and G-173C genotypes were clearly separated by SSCP. The 8-CATT allele was found in only two patients with gastric cancer. These polymorphisms were in significant linkage disequilibrium, with the $-173 \mathrm{C}$ allele strongly associated with the 7-CATT repeat allele. The most frequent haplotypes were -173G/5-CATT, -173G/6CATT and -173 C/7-CATT, which constituted $~ 90 \%$ of the haplotypes.

The characteristics and the frequencies of alleles in all 657 subjects are summarized in Table I. Compared to the non-GC group, the mean age, male/female ratio and $H$. pylori positivity were higher in the GC group.
The association between MIF promoter polymorphisms and gastric cancer. By using the unadjusted analysis, the 5-CATT allele carriers had a significantly reduced risk of developing gastric cancer (OR, 0.67; 95\% CI, 0.48-0.93; p=0.015), especially the diffuse type (Table II). In subjects $>60$ years old, the $-173 \mathrm{C}$ allele carriers had a significantly increased risk of developing gastric cancer, especially the intestinal type of gastric cancer, by using unadjusted and adjusted analyses (OR, 1.73; 95\% CI, 1.05-2.85 and OR, 2.10; 95\% CI, 1.17-3.75, respectively). The number of 7-CATT alleles was also positively correlated with the development of the intestinal type gastric cancer (OR, 1.70; 95\% CI, 1.02-2.58; $\mathrm{p}=0.043$ ). On the other hand, there were no significant associations between the MIF promoter polymorphisms and the development of gastric cancer in subjects $<60$ years old.

The association between the MIF promoter polymorphisms and clinicopathological features of gastric cancer. The frequency of the 7/7-CATT homozygous genotype in the lymph invasion-positive or venous invasion-positive cases was significantly higher compared to the non-GC group (Table III). In addition, the 5-CATT carriers had a reduced risk and the $-173 \mathrm{C}$ carriers had an increased risk for the peritoneal dissemination of cancer cells.

The association between the MIF promoter polymorphisms and chronic gastritis. The severity of histological gastritis was assessed in 420 out of 657 subjects. The frequency of the 7/7-CATT homozygous genotype in the atrophic gastritis group was significantly higher than that in the non-atrophy group. By using the adjusted analysis, 7/7-CATT homozygous genotype also had an increased risk of developing gastric mucosal atrophy in subjects $<60$ years old (OR, 8.74; 95\% CI, $1.31-58.6 ; \mathrm{p}=0.026)$. In addition, the number of 7-CATT alleles was positively correlated with the activity and 
Table III. Association between the MIF polymorphisms and clinicopathological features of gastric cancer.

\begin{tabular}{|c|c|c|c|c|c|c|}
\hline & \multicolumn{2}{|c|}{ 5-CATT carrier vs the others } & \multicolumn{2}{|c|}{ 7/7-CATT vs the others } & \multicolumn{2}{|c|}{$-173 \mathrm{C}$ carrier vs the others } \\
\hline & Unadjusted OR & Adjusted $\mathrm{OR}^{\mathrm{a}}$ & Unadjusted OR & Adjusted $\mathrm{OR}^{\mathrm{a}}$ & Unadjusted OR & Adjusted $\mathrm{OR}^{\mathrm{a}}$ \\
\hline \multicolumn{7}{|l|}{ Cancer stage } \\
\hline$\leq \mathrm{TI}$ & $0.83(0.52-1.30)$ & $0.73(0.44-1.20)$ & $1.02(0.22-4.82)$ & $0.77(0.15-3.79)$ & $1.13(0.72-1.78)$ & $1.17(0.72-1.92)$ \\
\hline$\geq \mathrm{T} 2$ & $0.88(0.54-1.43)$ & $0.92(0.55-1.55)$ & $1.84(0.49-6.95)$ & $1.72(0.42-7.01)$ & $1.12(0.69-1.83)$ & $1.15(0.69-1.93)$ \\
\hline \multicolumn{7}{|l|}{ Lymph invasion } \\
\hline Positive & $0.98(0.59-1.63)$ & $0.96(0.56-1.66)$ & $3.37(1.10-10.4)^{\mathrm{c}}$ & $2.76(0.84-9.09)$ & $1.19(0.72-1.96)$ & $1.22(0.72-2.07)$ \\
\hline Negative & $0.82(0.49-1.38)$ & $0.73(0.42-1.27)$ & $\mathrm{NC}$ & $\mathrm{NC}$ & $0.95(0.56-1.60)$ & $0.95(0.54-1.67)$ \\
\hline \multicolumn{7}{|l|}{ Venous invasion } \\
\hline Positive & $1.19(0.56-2.53)$ & $1.31(0.59-2.88)$ & $4.66(1.20-18.1)^{\mathrm{d}}$ & $4.64(1.07-20.1)^{\mathrm{e}}$ & $1.66(0.82-3.38)$ & $1.83(0.87-3.85)$ \\
\hline Negative & $0.83(0.54-1.27)$ & $0.75(0.47-1.19)$ & $0.86(0.18-4.05)$ & $0.61(0.12-3.03)$ & $0.93(0.60-1.43)$ & $0.91(0.57-1.47)$ \\
\hline \multicolumn{7}{|c|}{ Lymph node metastasis } \\
\hline Positive & $0.84(0.50-1.39)$ & $0.86(0.50-1.48)$ & $2.02(0.54-7.66)$ & $2.17(0.52-9.12)$ & $1.12(0.67-1.85)$ & $1.18(0.69-2.02)$ \\
\hline Negative & $0.86(0.55-1.34)$ & $0.78(0.48-1.26)$ & $0.95(0.20-4.47)$ & $0.69(0.14-3.38)$ & $1.13(0.73-1.76)$ & $1.16(0.72-1.88)$ \\
\hline \multicolumn{7}{|c|}{ Peritoneal dissemination } \\
\hline Positive & $0.43(0.19-0.98)^{\mathrm{b}}$ & $0.43(0.18-1.02)$ & $\mathrm{NC}$ & $\mathrm{NC}$ & $2.19(0.95-5.04)$ & $2.37(1.00-5.60)^{\mathrm{f}}$ \\
\hline Negative & $0.95(0.65-1.40)$ & $0.91(0.60-1.39)$ & $1.63(0.54-4.94)$ & $1.31(0.40-4.21)$ & $1.01(0.69-1.48)$ & $1.03(0.68-1.57)$ \\
\hline
\end{tabular}
${ }^{\mathrm{d}} \mathrm{p}=0.027,{ }^{\mathrm{e}} \mathrm{p}=0.041$ and ${ }^{\mathrm{f}} \mathrm{p}=0.050$.
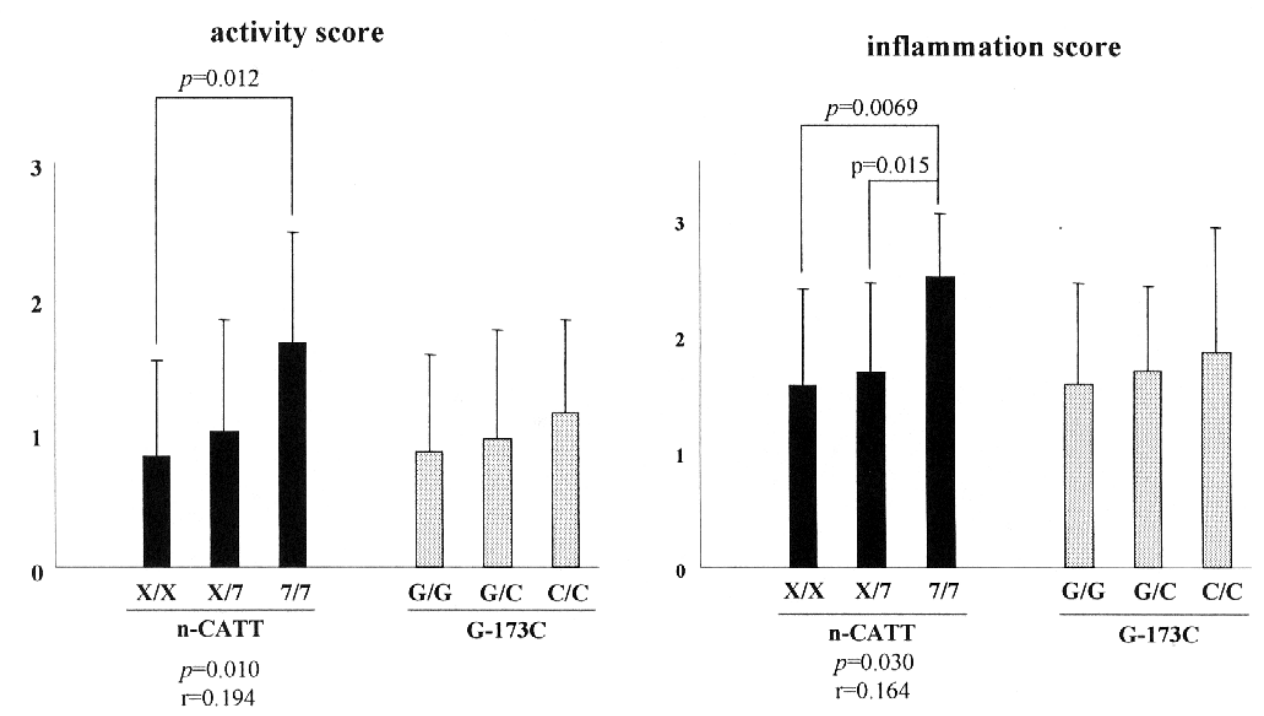

Figure 2. The association between promoter polymorphisms of the MIF gene and the activity or inflammation score in subjects $<60$ years old. The comparison between the two groups was performed by the Mann-Whitney U test and the associations between the number of 7-CATT alleles and each score was assessed by a linear regression analysis.

inflammation scores in subjects $<60$ years old ( $\mathrm{p}=0.010$ and 0.030 , respectively, Fig. 2), whereas no correlations were found in subjects $>60$ years old.

\section{Discussion}

Results from our study suggested that the 7-CATT repeat of the MIF gene promoter at position -794 was significantly associated with a risk for the severity of gastric mucosal inflammation in younger subjects and for the subsequent development of gastric mucosal atrophy. Furthermore, both the $-173 \mathrm{C}$ allele and 7-CATT together were found to confer a higher risk of developing gastric cancer, especially the intestinal type of gastric cancer, in older ( $>60$ years old) subjects. Since the $-173 \mathrm{C}$ allele was strongly associated with the 7-CATT repeats, the $-173 \mathrm{C} / 7$-CATT haplotype may be 
Table IV. Association between the MIF polymorphisms and gastric mucosal atrophy.

\begin{tabular}{|c|c|c|c|c|c|c|}
\hline & \multicolumn{2}{|c|}{ 5-CATT carrier vs the others } & \multicolumn{2}{|c|}{ 7/7-CATT vs the others } & \multicolumn{2}{|c|}{$-173 \mathrm{C}$ carrier vs the others } \\
\hline & Unadjusted OR & Adjusted OR ${ }^{\mathrm{a}}$ & Unadjusted OR & Adjusted OR ${ }^{\mathrm{a}}$ & Unadjusted OR & Adjusted $\mathrm{OR}^{\mathrm{a}}$ \\
\hline Overall subjects & $1.00(0.67-1.51)$ & $0.89(0.56-1.42)$ & $3.12(1.00-9.71)^{\mathrm{b}}$ & $3.47(0.96-12.6)$ & $0.98(0.65-1.47)$ & $0.98(0.62-1.55)$ \\
\hline$\leq 60$ years & $1.21(0.61-2.41)$ & $0.85(0.40-1.85)$ & $5.08(0.90-28.7)$ & $8.74(1.31-58.6)^{\mathrm{c}}$ & $0.90(0.46-1.74)$ & $0.90(0.43-1.86)$ \\
\hline$>60$ years & $0.94(0.56-1.58)$ & $0.88(0.49-1.61)$ & $2.18(0.48-9.96)$ & $2.01(0.35-11.4)$ & $1.03(0.61-1.72)$ & $1.14(0.63-2.09)$ \\
\hline
\end{tabular}

The frequency of genotype was compared between the atrophic gastritis group (atrophy score $\geq 2$ ) and non-atrophy group (atrophy score $\leq 1$ ). ${ }^{a}$ Adjusted for gender, age and the $H$. pylori infection status. Data are shown as OR (95\% confidence intervals); ${ }^{b} \mathrm{p}=0.050$ and ${ }^{\mathrm{c}} \mathrm{p}=0.026$.

associated with gastric carcinogenesis. In addition, the 5CATT allele carriers had a reduced risk for developing gastric cancer, especially the diffuse type cancer.

It is generally believed that MIF functions as a cytokine to promote the recruitment of neutrophils and macrophages and the migration of these cells to the site of inflammation (22). MIF is involved in T cell proliferation by promoting the secretion of interleukin-2 (23) and can deliver a priming signal to neutrophils to mobilize them into producing an immediate and robust response in the presence of pathogens (24). In addition, MIF can induce production of the tumor necrosis factor and inducible nitric oxide (25). Through these effects on inflammation, an important role of MIF on gastric disorders has been shown, such as gastric inflammation (15), ulcer (24) and carcinogenesis (26). However, there is no report regarding the association between functional promoter polymorphisms of the MIF gene and gastric disorders, although several studies have shown significant associations of these polymorphisms with cystic fibrosis (27), psoriasis (28), atopic disorders (29) and inflammatory bowel disease (30).

Baugh et al have reported the correlation of the -794 5CATT repeat with low disease severity in rheumatoid arthritis patients (18) and Hizawa et al have also reported an increased risk of non-794 5-CATT carriers for atopy (28). Donn et al have demonstrated that the $-173 \mathrm{C} / 7-\mathrm{CATT}$ haplotype is of importance in the susceptibility to psoriasis (16). Thus, 5CATT seems to correlate with low inflammation severity, whereas 7-CATT seems to be associated with an increased risk for inflammation. These results support our results that 7-CATT was associated with the severity of gastric inflammation and with the development of gastric mucosal atrophy.

The promoter sequence analysis indicates that the $-173 \mathrm{C}$ allele creates a potential activator protein- 4 transcription-factor binding site (16) and levels of the MIF expression significantly differed among the G-173C genotypes in a cell-type manner. Regarding the CATT repeats, the 5-CATT allele was shown to be associated with a lower basal and stimulated MIF promoter activity in vitro than 6-, 7- and 8-CATT alleles. Donn et al have shown that an increasing CATT repeat with the $-173 \mathrm{C}$ allele significantly increased the promoter activity in a T lymphoblast cell line (17). Thus, the $-173 \mathrm{C}$ and 7-CATT haplotype together seemed to promote the maximal production of MIF and the 7-CATT allele may thus promote the development of gastric inflammation and mucosal atrophy.
Since we found significant interactions between the age and the number of -173C and 7-CATT alleles by ANCOVA ( $\mathrm{p}=0.037$ and 0.019 , respectively), the age-specific analysis was performed. Then, a significant relationship between the number of 7-CATT alleles and the inflammatory cell infiltrations was seen only in subjects $<60$ years old. It has been shown that long-term exposure to $H$. pylori is a significant risk factor for the progression of atrophic and metaplastic gastritis $(31,32)$. In older subjects, gastric mucosal inflammation may decrease because of the progression of gastric atrophy and metaplasia. In addition, a lower serum MIF level was exhibited in older rats (33). Therefore, MIF may promote the gastric mucosal inflammation at an early stage in life, whereas it may not in older subjects. As a result, gastric mucosal atrophy may develop at an earlier age in the 7-CATT carriers.

According to the Lauren classification (34), there are two histologically distinct types of gastric cancer. The intestinal type consists of gland-like structures that mimic the intestinal glands and a series of precancerous lesions are recognized. The diffuse type of gastric cancer lacks any glandular structures and arises closer to the advancing edge of the gastric mucosal inflammation without any identifiable histological precursor lesion (35). The former develops in the stomach affected by chronic inflammation and passes through the intermediate steps of atrophic gastritis or intestinal metaplasia (36). On the other hand, the severity of mucosal inflammation and various host features may directly induce mutagenetic events that ultimately lead to the onset of the latter. Our findings suggested that the $-173 \mathrm{C} / 7-\mathrm{CATT}$ haplotype may be related to the severity of gastric mucosal atrophy at a younger age because of the more strongly activated MIF gene expression and may increase the risk for the development of gastric mucosal atrophy-related disorders, such as the intestinal type of gastric cancer, at an older age. The 5-CATT allele may suppress the gastric mucosal inflammation that leads to the progression of the diffuse type gastric cancer.

In conclusion, the present study demonstrated that the 7CATT repeat and $-173 \mathrm{C}$ allele of the MIF gene promoter was associated with the progression of gastric mucosal inflammation and the development of gastric mucosal atrophy in younger subjects and these allele carriers may have an increased risk for the subsequent development of gastric cancer, especially the intestinal type. The 5-CATT repeat may reduce the risk for the development of diffuse type gastric cancer via decreased gastric inflammation. 


\section{Acknowledgements}

This study was supported, in part, by a Grant-in-Aid for the 21st Century Center of Excellence Program of Fujita Health University from the Ministry of Education, Culture, Sports, Science and Technology of Japan.

\section{References}

1. Suerbaum S and Michetti P: Helicobacter pylori infection. N Engl J Med 347: 1175-1186, 2002.

2. Blaser MJ and Berg DE: Helicobacter pylori genetic diversity and risk of human disease. J Clin Invest 107: 767-773, 2001.

3. Prinz C, Schoniger M, Rad R, et al: Key importance of the Helicobacter pylori adherence factor blood group antigen binding adhesin during chronic gastric inflammation. Cancer Res 61: 1903-1909, 2001.

4. Ernst PB and Gold BD: The disease spectrum of Helicobacter pylori: the immunopathogenesis of gastroduodenal ulcer and gastric cancer. Ann Rev Microbiol 54: 615-640, 2000.

5. Shimoyama T and Crabtree JE: Bacterial factors and immune pathogenesis in Helicobacter pylori infection. Gut 43: S2-S5, 1998.

6. Yamaoka Y, Kita M, Kodama T, et al: Induction of various cytokines and development of severe mucosal inflammation by CagA positive Helicobacter pylori strains. Gut 41: 442-451, 1997.

7. Rad R, Gerhard M, Lang R, et al: The Helicobacter pylori blood group antigen-binding adhesion facilitates bacterial colonization and augments a nonspecific immune response. J Immunol 168: 3033-3041, 2002.

8. Shibata J, Goto H, Arisawa T, et al: Regulation of tumour necrosis factor (TNF) induced apoptosis by soluble TNF receptors in Helicobacter pylori infection. Gut 45: 24-31, 1999.

9. Bloom BR and Bennett B: Mechanism of a reaction in vitro associated with delayed-type hypersensitivity. Science 153: 80-82, 1966.

10. David JR: Delayed hypersensitivity in vitro: its mediation by cell-free substances formed by lymphoid cell-antigen interaction. Proc Natl Acad Sci USA 56: 72-77, 1966.

11. Weiser WY, Temple PA, Witek-Giannotti JS, Remold HG, Clark SC and David JR: Molecular cloning of a cDNA encoding a human macrophage migration inhibitory factor. Proc Natl Acad Sci USA 86: 7522-7526, 1989.

12. Lue H, Kleemann R, Calandra T, Roger T and Bernhagen J: Macrophage migration inhibitory factor (MIF): Mechanisms of action and role in disease. Microb Infect 4: 449-460, 2002.

13. Calandra T, Echtenacher B, Roy DL, et al: Protection from septic shock by neutralization of macrophage migration inhibitory factor. Nat Med 6: 164-170, 2000.

14. Donnelly SC, Haslett C, Reid PT, et al: Regulatory role for macrophage migration inhibitory factor in acute respiratory distress syndrome. Nat Med 3: 320-323, 1997.

15. Bucala R and Donelly SC: Macrophage migration inhibitory factor: a probable link between inflammation and cancer. Immunity 26: 281-285, 2007.

16. Xia HHX, Lam SK, Huang XR, et al: Helicobacter pylori infection is associated with increased expression of macrophage migration inhibitory factor by epithelial cells, T cells and macrophages in gastric mucosa. J Infect Dis 190: 293-302, 2004.

17. Donn R, Alourfi Z, De Benedetti F, et al: Mutation screening of the macrophage migration inhibitory factor gene: positive association of a functional polymorphism of macrophage migration inhibitory factor with juvenile idiopathic arthritis. Arthritis Rheum 46: 2402-2409, 2002.
18. Baugh JA, Chitnis S, Donnelly SC, et al: A functional promoter polymorphism in the macrophage migration inhibitory factor (MIF) gene associated with disease severity in rheumatoid arthritis. Genes Immunol 3: 170-176, 2002.

19. Amoli MM, Donn RP, Thomson W, et al: Macrophage migration inhibitory factor gene polymorphism is associated with sarcoidosis in biopsy proven erythema nodosum. J Rheumatol 29: 1671-1673,2002.

20. Arisawa T, Tahara T, Shibata T, et al: The relationship between Helicobacter pylori infection and promoter polymorphism of the Nrf2 gene in chronic gastritis. Int J Mol Med 19: 143-148, 2007.

21. Arisawa T, Tahara T, Shibata $\mathrm{T}$, et al: A polymorphism of microRNA 27 a genome region is associated with the development of gastric mucosal atrophy in Japanese male subjects. Dig Dis Sci 52: 1691-1697, 2007.

22. Swope MD and Lolis E: Macrophage migration inhibitory factor: cytokine, hormone, or enzyme? Rev Physiol Biochem Pharmacol 139: 1-32, 1999.

23. Backer M, Metz C, CaIandra T, et al: An essentiaI role for MIF in $\mathrm{T}$ cell activation. Proc Natl Acad Sci USA 93: 7849-7854, 1996.

24. Swope M, Sun HW, BIake P, et al: Direct link between cytokine activity and a catalytic site for macrophage migration inhibitory factor. EMBO J 17: 3534-3541, 1998.

25. Huang XR, Chun Hui CW, Chen YX, et al: Macrophage migration inhibitory factor is an important mediator in the pathogenesis of gastric inflammation in rats. Gastroenterology 121: 619-630, 2001 .

26. He XX, Yang J, Ding YW, Liu W, Shen QY and Xia HH: Increased epithelial and serum expression of macrophage migration inhibitory factor (MIF) in gastric cancer: potential role of MIF in gastric carcinogenesis. Gut 55: 797-802, 2006.

27. Plant BJ, Gallagher CG, Bucala R, et al: Cystic fibrosis, disease severity, and a macrophage migration inhibitory factor polymorphism. Am J Respir Crit Care Med 172: 1412-1415, 2005.

28. Donn RP, Plant D, Jury F, et al: Macrophage migration inhibitory factor gene polymorphism is associated with psoriasis. J Invest Dermatol 123: 484-487, 2004.

29. Hizawa N, Yamaguchi E, Takahashi D, Nishihara J and Nishimura M: Functional polymorphisms in the promoter region of macrophage migration inhibitory factor and atopy. Am J Respir Crit Care Med 169: 1014-1018, 2004.

30. Oliver J, Marquez A, Gomez-Garcia M, et al: Association of the macrophage migration inhibitory factor gene polymorphisms with inflammatory bowel disease. Gut 56: 150-151, 2007.

31. Kawaguchi H, Haruma K, Komoto K, Yoshihara M, Sumii K and Kajiyama G: Helicobacter pylori infection is the major risk factor for atrophic gastritis. Am J Gastroenterol 91: 959-962, 1996.

32. Kuipers EJ, Uyterlinde AM, Pena AS, et al: Long-term sequelae of Helicobacter pylori gastritis. Lancet 345: 1525-1528, 1995.

33. Sakamoto W, Isomura H, Fujie K, et al: The effect of vitamin $\mathrm{K} 2$ on bone metabolism in aged female rats. Osteoporos Int 16: 1604-1610, 2005.

34. Lauren P: The two histologic main types of gastric carcinoma: diffuse and so-called intestinal type carcinoma. An attempt at a histo-clinical classification. Acta Pathol Microbiol Scand 64: 31-49, 1965

35. Yoshimura T, Shimoyama T, Fukuda S, Tanaka M, Axon AT and Munakata A: Most gastric cancer occurs on the distal side of the endoscopic atrophic border. Scand J Gastroenterol 32: 377-382, 1999.

36. Go MF: Review article: Natural history and epidemiology of Helicobacter pylori infection. Aliment Pharmacol Ther 16: 3-15, 2002 . 